\title{
Candida esophagitis in a male homosexual with defective neutrophil function. A "pseudo-AIDS" syndrome
}

\author{
Michael A. Noble, MD, FrCP(C), J. Scott Whittaker. MD, FrCP(C), Anil K. Mangal. MD, FrCP(C), \\ Cedric J. Carter, MD, FrCP(C), Hugh J. Freeman MD, FRCP(C), FACP
}

\begin{abstract}
A 36-year-old male homosexual presented with a prolonged history of odynophagia. Esophageal candidiasis was suspected at endoscopy and confirmed by biopsy and cultures. Investigations demonstrated no evidence for underlying human immunodeficiency virus (HIV) infection by either ELISA assay or Western Blot technique, and lymphocyte helper: supressor ratios were normal. A specific serum-dependent factor that inhibited the candidacidal capability of his neutrophils, as well as those of volunteer controls, was detected. This inhibitor disappeared after treatment of the candidal infection. Severe and extensive esophagitis is not always indicative of an underlying infection with HIV in homosexual males. Clinical criteria alone should not be used to establish the diagnosis of AIDS, even in patients from recognized high risk categories. Can J Gastroenterol 1987;1(1):33-35
\end{abstract}

Key Words: Acquired immune deficiency syndrome (AIDS), Candida esophagitis, Neutrophil function
A CQUIRED IMMUNE DEFICIENCY SYNdrome (AIDS) commonly presents with an opportunistic infection, often involving the gastrointestinal tract. Candida esophagitis is a very common presenting feature in this setting (1) and candidiasis, if severe and present in an individual from a high risk category, has been considered a diagnostic clinical marker for the presence of AIDS itself (2). This paper presents a male homosex- ual with extensive candida esophagitis but no underlying human immunodeficiency virus (HIV) infection. Subsequent studies defined a specific but reversible impairment in neutrophil function resulting in defective candidacidal activity.

\section{CASE REPORT}

A 36-year-old homosexual male presented with a six-month history of odynophagia. He was treated initially with
Departments of Pathology (Medical Microbiology) and Medicine (Gastroenterology), University of British Columbia and the Health Sciences Centre Hospital, Vancouver, British Columbia

Correspondence: Dr Hugh J. Freeman, UBC Health Sciences Centre Hospital, 2211 Wesbrook Mall,

Vancouver, British Columbia, V6T IW5. Telephone (604) 228-7216

Received for publication March 11, 1987. Accepted May 14, 1987 cimetidine and then ranitidine with only transient symptomatic relief. Although he had been a member of the gay community for eight years, he had been sexually inactive for the past five years. There was no history of intravenous drug use, but he had a previous history of hepatitis B and genital herpes infections.

Physical examination throughout his course was normal; hepatosplenomegaly and palpable enlargement of lymph nodes were not present. Laboratory investigations demonstrated an initial iron deficiency anemia (hemoglobin $1.302 \mathrm{mmol} /$ $\mathrm{L}$, mean corpuscular volume, $73 \mathrm{fl}$, mean corpuscular hemoglobin concentration 0.308 , serum ferritin $14 \mathrm{mg} / \mathrm{mL}$ ) with no abnormality in total white cell count or platelets. White cell differential and morphology were normal. Aspiration of bone marrow showed no stainable iron. Other investigations, including blood sugars and renal and liver blood chemistries, were normal.

Because of persistent symptoms, the patient was referred for further evaluation. Fibreoptic endoscopy revealed discrete elevated plaques, typical of exudate associated with esophageal candidiasis. The changes were severe and extended the entire length of the esophagus. The stomach and duodenum were normal. 


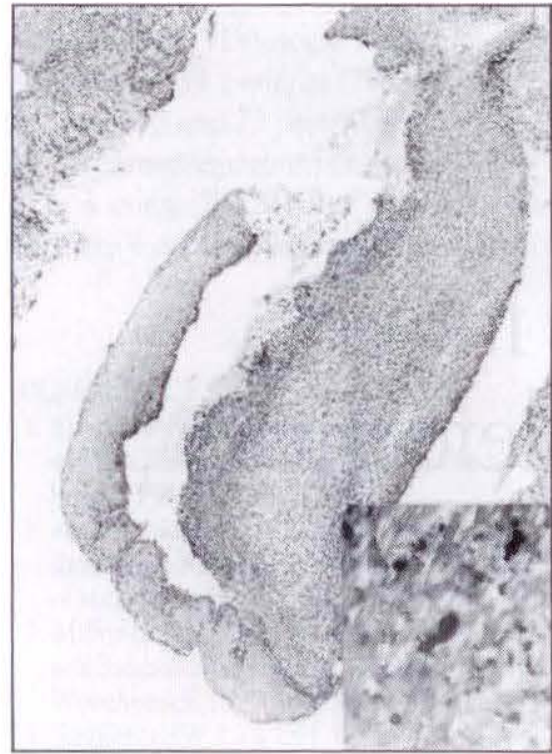

Figure 1) Biopsy of esophagus demonstrating inflammatory exudate with budding yeast typical of Candida species infection $\times 6$. (Inset $\times 57$ )

Esophageal biopsies demonstrated budding yeasts in ulcer exudate (Figure 1) and cultures of biopsy material grew Candida krusei. Superimposed Herpes simplex and cytomegalovirus were excluded by negative viral cylture and immunostaining of endoscopic biopsies $(3,4)$. Viral particles. including those recently described resembling retroviral particles (5), were not observed on electron microscopic studies of esophageal biopsies. Blood cultures for fungi were negative.

Antifungal therapy was initiated with oral mycostatin. Because of continued severe odynophagia, this was changed to ketoconazole and then to intravenous amphotericin B with only limited improvement. After repeat endoscopy showed continued presence of exudative plaques superimposed on numerous linear ulcers from the middle to distal esophagus, oral clotrimazole was administered for four weeks (6). A further endoscopic study demonstrated a marked reduction in the number of plaques with mucosal healing. Clotrimazole was discontinued and repeat endoscopic studies two and 12 months later revealed complete resolution.

Because of the severity of the clinical presentation, consistent with recent criteria for definition of AIDS (2), the patient's serum was sent to the National AIDS Laboratory, Laboratory Centre for Disease Control, Ottawa, Ontario, for lab- oratory confirmation. On two occasions, each separated by six months, no evidence for HIV antibody was detected by ELISA assay (Electro-Nucleonics Inc, Columbia, Maryland) or by Western Blot technique (7). In addition, the OKT4/OKT8 lymphocyte subset ratio was normal.

Additional studies were done to exclude an immunologic defect. Measurement of serum immunoglobulins revealed a reduced concentration of $\operatorname{lgG}(5.5 \mathrm{~g} / \mathrm{L}$; normal, 8 to $18 \mathrm{~g} / \mathrm{L}$ ) but normal $\operatorname{IgA}$ and $\mathrm{IgM}$ as well as normal complement (C3, $1.96 \mathrm{~g} / \mathrm{L}$; normal, 0.7 to $1.6 \mathrm{~g} / \mathrm{L}$; and $\mathrm{C} 4$. $0.41 \mathrm{~g} / \mathrm{L}$; normal, 0.16 to $0.45 \mathrm{~g} / \mathrm{L}$ ).

Neutrophil candidacidal activity was also determined (8). This was done during active infection off all medications for at least $96 \mathrm{~h}$ and repeated two months after completion of antifungal therapy. An abnormality in candidacidal activity was noted during active infection (Table 1); this disappeared after treatment. The defect was serum-associated; control volunteers' neutrophils incubated with patient serum also showed defective candidacidal activity. For both patient and control cells, this defect was corrected with control serum. When tested again two months after clinical recovery, no serum-associated abnormality could be detected.

To determine if this serum defect was due to the presence of an inhibitor rather than a serum factor deficiency, serial serum dilutions were done during the phase of active infection. Killing capacity increased with increasing dilution until excessive dilution occurred (Table 2), indicating the serum defect to be solely or predominantly due to an inhibitor. Had
TABLE 2

Effect of serial dilutions on patient's serum candidacidal activity

\begin{tabular}{cc}
\hline Serum dilution ${ }^{*}$ & Candidacidal activityt \\
\hline $1: 1$ & 10.0 \\
$1: 10$ & 23.2 \\
$1: 20$ & 40.2 \\
$1: 40$ & 21.0 \\
\hline
\end{tabular}

- Dilutions of patient serum with Hank's solution †Candidacidal activity expressed as percentage of patient's yeast killed by normal control cells after incubation with increasing dilutions of pa. tient's serum

the defect been caused by a deficiency alone, increasing dilution would have resulted in a progressive reduction in killing capacity.

Additional standard neutrophil function studies (9) were done. Measurements of chemotaxis in agarose, phagocytosis and bacteriocidal activity against Staphylococcus aureus NCTC 6571 were normal.

\section{DISCUSSION}

Candida esophagitis is a common presenting manifestation in AIDS (1,2,10-12). A dense white lesion is characteristic, extending into the upper third of the esophagus, and often associated with oral thrush $(12,13)$. Klein et al (10) observed the presence of unexplained oral candidiasis in 22 homosexual males; 19 had an abnormally low T4/T8 ratio at the onset of their illness. Within two years, 13 had already acquired a further major opportunistic infection or Kaposi's sarcoma as further evidence of AIDS. Our patient, presenting as a member of a high risk group, had extensive and severe esophageal candidiasis; this ordinarily would lead

\section{TABLE 1}

Neutrophil candidacidal activity from heparinized blood of the patient and two healthy control volunteers using Dextran sedimentation

\begin{tabular}{|c|c|c|c|c|}
\hline & \multicolumn{4}{|c|}{ Test sample } \\
\hline & $\begin{array}{l}\text { Patient cells/ } \\
\text { patient serum }\end{array}$ & $\begin{array}{l}\text { Patient cells/ } \\
\text { control serum }\end{array}$ & $\begin{array}{l}\text { Control cells/ } \\
\text { patient serum }\end{array}$ & $\begin{array}{l}\text { Control cells/ } \\
\text { control serum }\end{array}$ \\
\hline \multicolumn{5}{|l|}{ During } \\
\hline infection ${ }^{*}$ & $13.0+$ & 18.4 & 12.0 & 18.4 \\
\hline \multicolumn{5}{|l|}{ After } \\
\hline treatmentt & 15.9 & 16.0 & 18.4 & 19.0 \\
\hline
\end{tabular}


to serious concern for a diagnosis of AIDS. Subsequent laboratory studies, however, demonstrated defective neutrophil candidacidal activity rather than a reduction in helper T-lymphocytes. Moreover, the absence of a serological marker for HIV infection over a six-month period as well as a normal T lymphocyte helper:suppressor ratio suggests that the host defect identified in this homosexual patient differed from that described in AIDS. Finally, the clinical illness, despite its extensive nature and severity, as well as the neutrophil defect, were completely reversible.

The neutrophil abnormality of this

\section{REFERENCES}

1. Centers for Disease Control. Update: Acquired immunodeficiency syndrome - United States. Morbidity Mortality Weekly Reports 1986; 35:17-20.

2. Centers for Disease Control. Revision of the case definition of acquired immunodeficiency syndrome for national reporting - United States. Ann Intern Med 1985; 103:402-3.

3. Freeman HJ, Shnitka TK, Piercey JRA, Weinstein WM. Cytomegalovirus infection of the gastrointestinal tract in a patient with late onset immunodeficiency syndrome. Gastroenterology 1977: 73:1397-463.

4. Sacks S, Freeman HJ. Cytomegalovirus hepatitis. Evidence for direct hepatic viral infection using monoclonal antibodies. Gastroenterology 1984: 86:346-50.

5. Rabeneck L, Boyko WJ, Mclean DM, Mcleod WA, Wong KK. Unusual esophageal ulcers containing enveloped virus like particles in homosexual men. Gastroenterology 1986; 90:1882-9.

6. Rabeneck L. Esophageal candidiasis in AIDS patients. Therapy with clotrimazole. Clin Invest Med 1985; 8:A95.

7. Esteban JI, Shih JW, Tai C, Bodner AI. Kay JWD. Alter JH. Importance of Western Blot analysis in predicting infectivity of anti-HTLV-III/LAV positive blood. Lancet 1985; ii: 1083-6.

8. Lehrer RFI, Cline MJ. Interaction of patient appeared to be specific for candidacidal activity and was associated with the presence of a serum inhibitor. The presence of plasma factors that inhibit the host response to fungi have been detected in patients with chronic mucocutaneous candidiasis (14-17), systemic candidiasis (18), diabetes mellitus (19) and systemic aspergillosis (20). Although this patient had a selective reduction in serum $\lg G$, no other common stigmata seen in chronic mucocutaneous candidiasis was present; he had no signs of hyperkeratosis or onychomycosis, no history of childhood or recurrent infections and no evidence for a lymphocyte defect. Late onset chronic mucocutaneous candidiasis is frequently associated with thymoma or endocrinopathies (21); these were not present. Other known predisposing factors (22) for esophageal candidiasis as well as other opportunistic infections, were excluded.

The patient, now completely well, illustrates that clinical criteria alone should not be used to establish a diagnosis of AIDS, even in high risk patient groups. Alternative mechanisms for opportunistic infections in homosexual males should be explored and considered in those patients who are HIV negative
Candida albicans with human leukocytes and serum. J Bact 1969;98:996-1004

9. Wilkinson PC. Neutrophil function tests. In: Techniques in Clinical Immunology 2nd edn. Thompson RA, ed. Oxford: Blackwell Scientific Publications, 1981:273-93.

10. Klein RS. Harris CA. Small CB. Moll B. Lesser M, Friedland GH. Oral candidiasis in high risk patients as the initial manifestation of the acquired immunodeficiency syndrome. N Engl J Med 1984 : 311:354-8

11. Tavitian A. Raufman J-P. Rosenthal LE. Oral candidiasis as a marker for esophageal candidiasis in the acquired immunodeficiency syndrome. Ann Intern Med 1986; 104:54-5

12. Tavitian A, Raufman J-P. Rosenthal LE, Weber J, Webber CA, Dinscoy HP. Ketoconazole-resistant candida esophagitis in patients with acquired immunodeficiency syndrome. Gastroenterology 1986; 90:443-5

13. Kodsi BE, Wickremisinghe PC, Kozinn PJ, Iswara K, Goldberg PK. Candida esophagitis; a prospective study of 27 cases. Gastroenterology 1976; 71:715-9

14. Kennedy CTC, Valdimarsson H. Hay RJ. Chronic mucocutaneous candidiasis with a serum-dependent neutrophil defect: response to ketoconazole. J Roy Soc Med $1981 ; 74: 162$.
15. Murphy JF, Jones M. Thompson EN Esophageal candidiasis and croup in a child with defective neutrophil motility. J Infect 1985; 8:247-50.

16. Van der Meer JWM, Leij PCJ, Van den Barselaar H. Van Furth R. Functions of phagocytic cells in chronic mucocutaneous candidiasis. Br Med J 1978: 1:147-8.

17. Walker SM, Urbaniak SJ. A serumdependent defect of neutrophil function in chronic mucocutaneous candidiasis. J Clin Path 1980; 33:370-2.

18. LaForce FM. Mills DM, Iverson K. Cousins R, Everett ED. Inhibition of leukocyte candidacidal activity by serum from patients with disseminated candidiasis. J Lab Clin Med 1975; 86:658-66

19. Raith L, Csato M, Dobozy A. Decreased Candida albicans killing activity of granulocytes from patients with diabetes mellitus. Mykosen 1983; 26:557-64

20. Pagani A, Spalla R, Ferrari FA, et al. Defective Aspergillus killing by neutrophil leukocytes in a case of systemic aspergillosis. Clin Exp Imm 1981 43:201-7.

21. Kirkpatrick $\mathrm{CH}$, Windhorst DB Mucocutaneous candidiasis and thym. oma. Am J Med 1979; 66:939-45

22. Kirkpatrick $\mathrm{CH}$. Host factors in defence against fungal infections. Am J Med 1984: 77. (4D): $1-12$ 


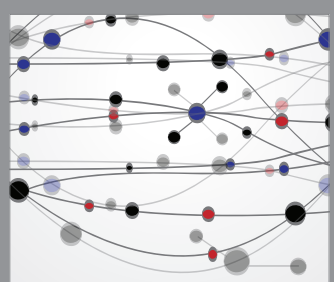

The Scientific World Journal
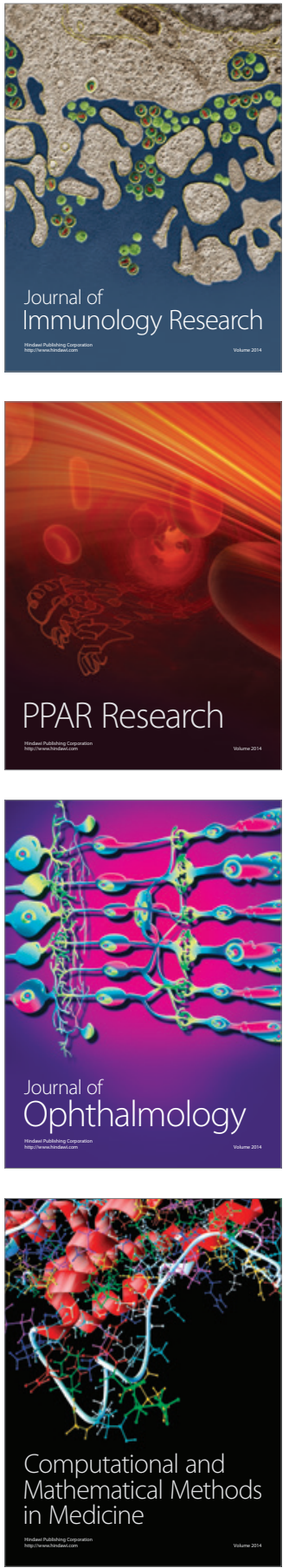

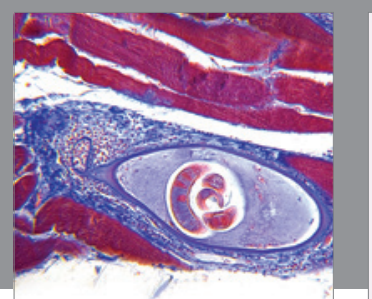

Gastroenterology Research and Practice

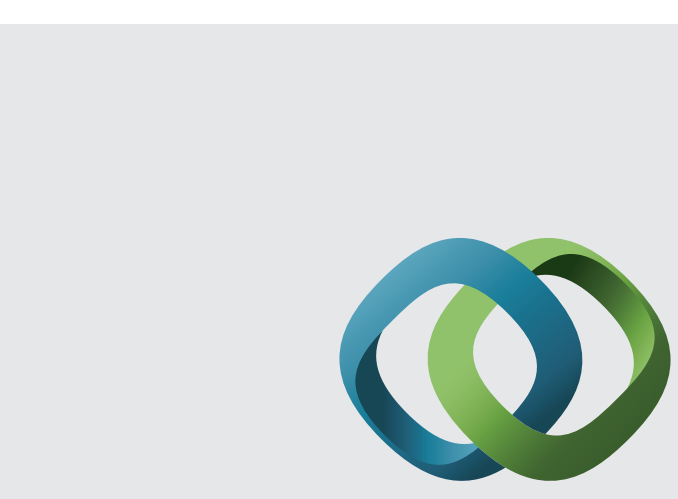

\section{Hindawi}

Submit your manuscripts at

http://www.hindawi.com
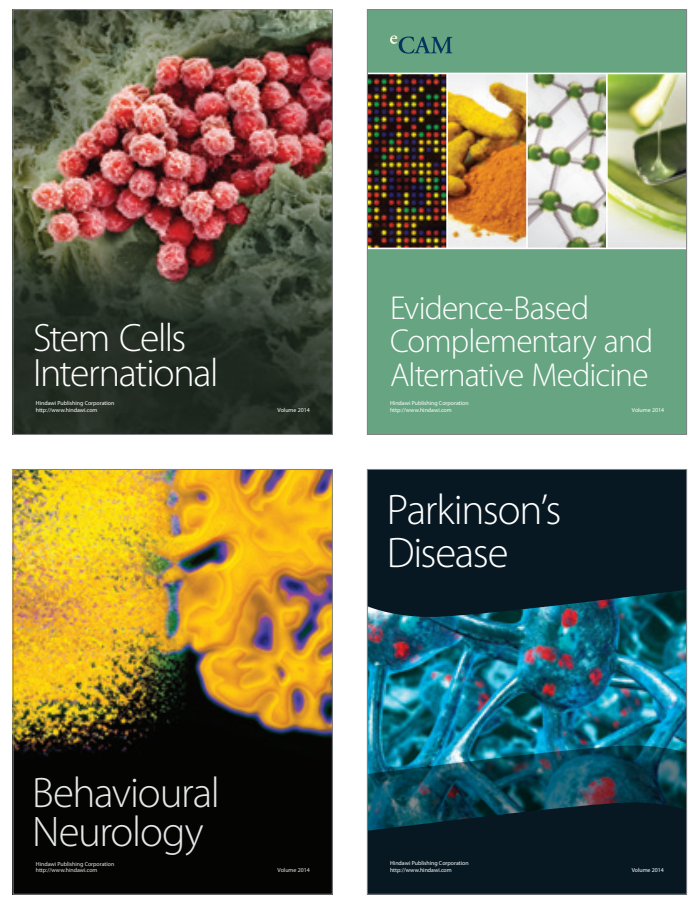
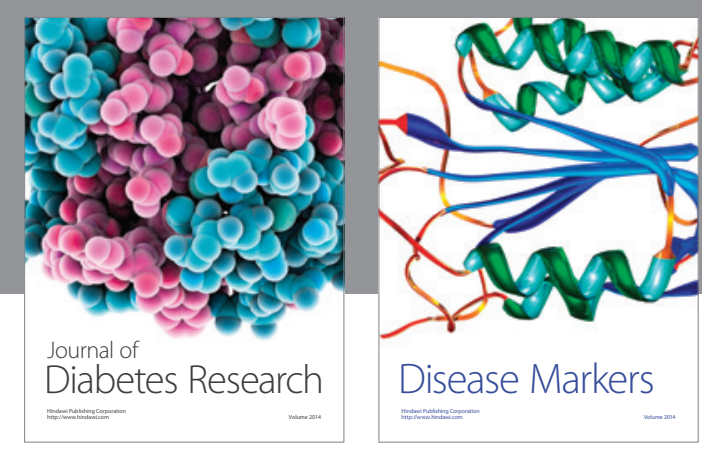

Disease Markers
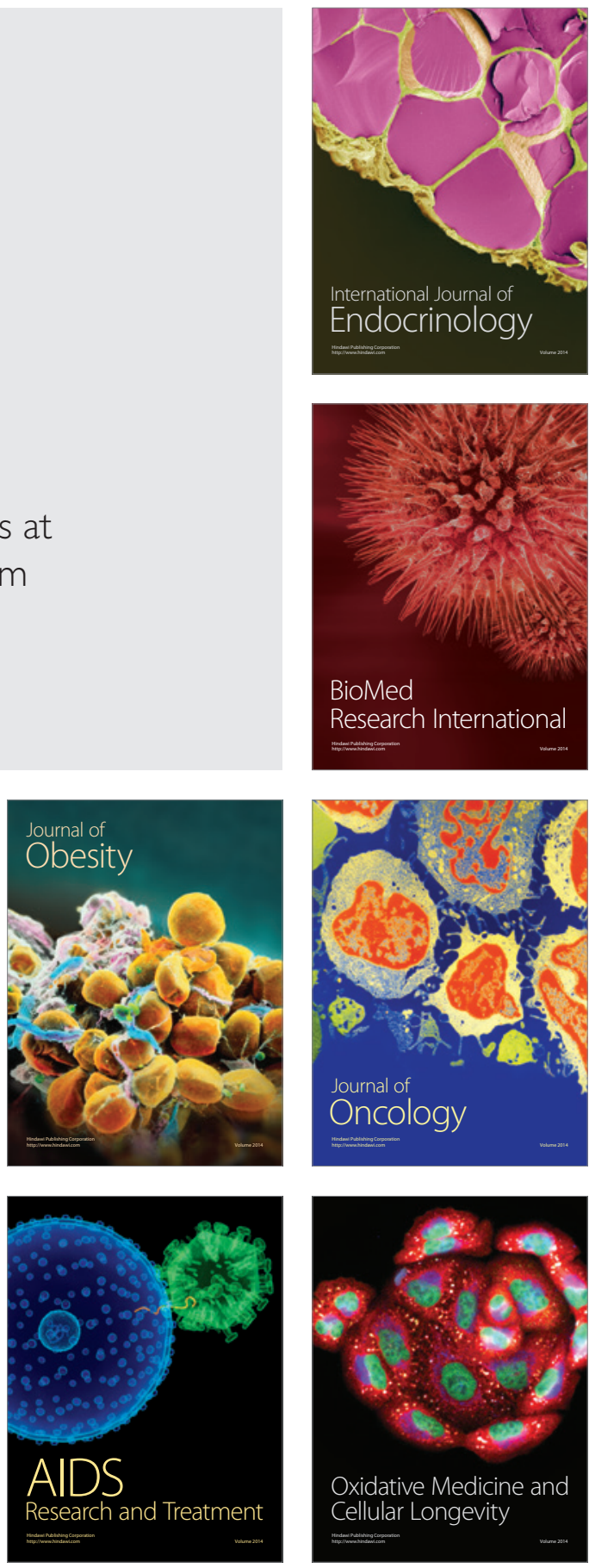